\title{
Design, Synthesis, Physicochemical and Immunological Characterization of Dendrimer-HBsAg Conjugate
}

\author{
Mohammad Sadeq Khosravy ${ }^{1,2}$, Mehdi Shafiee Ardestani ${ }^{3 *}$, Reza Ahangari Cohan ${ }^{5}$, Delaram Doroud ${ }^{4}$, Safieh Amini $^{1}$, \\ Seyed Bahman Momen ${ }^{5}$, Seyed Mohammad Atyabi ${ }^{5}$, Hossien Heydari ${ }^{4}$, Rohollah Vahabpour ${ }^{1}$
}

\begin{abstract}
1 Department of Hepatitis and AIDS, Pasteur Institute of Iran, Tehran, Iran.
2 Department of Laboratory Animal Sciences, Production and research Complex, Pasteur Institute of Iran, Tehran, Iran.

3 Department of Radiopharmacy, Faculty of Pharmacy, Tehran University of Medical Sciences, Tehran, Iran.

4 Department of Quality Assurance, Production and research Complex, Pasteur Institute of Iran, Tehran, Iran.

5 Department of Pilot Biotechnology, Pasteur Institute of Iran, Tehran, Iran.
\end{abstract}

Accepted Mar 10, 2015

\begin{abstract}
Introduction: Manufacturing new Hepatitis B virus vaccines, specifically by the use of nanoparticles, is of high global interest. In this paper, a new structure of nano-sized hepatitis B virus' surface antigen (HBsAg) was generated by conjugation with dendrimers. Methods: The physicochemical properties of the conjugate were characterized by zeta potential and size distribution analyses and FT-IR spectrometry. Results: The results confirmed the conjugation between HBsAg and the dendrimers. Immunological assays indicated that the immunogenicity of the conjugated HBsAg is more than HBsAg alone. Conclusion: In the current study, a costeffective, biodegradable and biocompatible polymer was used to enhance the immunogenicity of HBsAg. Also, further investigations are required to explore the mechanisms of action of this nanocomplex vaccine candidate.
\end{abstract}

KEYWORDS: HBsAg, Dendrimers, Vaccine, Conjugate

\section{INTRODUCTION}

Hepatitis B virus (HBV) infection is a major global health problem. More than 240 million people are chronically infected with HBV and an estimated 600'000 die each year from the consequences of this infection, worldwide $[1,2]$. Among the infected patients, $15 \%-40 \%$ of them will succumb to liver fibrosis, cirrhosis and finally hepatocellular carcinoma [3]. Vaccination against hepatitis $B$ is one of the success stories in modern medicine [4] and the mainstay control of HBV is by preventing the infection, following acute and chronic liver diseases. Since more than 20 years ago, several clinical trials exploited the conventional prophylactic means (i.e. protein vaccine, T-cell vaccine and combination therapy), based on hepatitis B surface antigen ( $\mathrm{HBsAg}$ ) for therapeutic vaccination [5-22]. Immunogenic complexes activate $\mathrm{T}$ cell responses by accumulating uptake of $\mathrm{HBsAg}$ through $\mathrm{Fc}$ receptors on antigen-presenting cells and then, enhance HBsAg processing and presentation. It has been demonstrated that this vaccine administered to HBsAg-positive patients could lead to decrease of HBV DNA in serum and HBsAg seroconversion in some patients [23]. The vaccines do not frequently present good immunogenic properties as seen by native microorganisms and

*Corresponding Author: Mehdi Shafiee Ardestani, Ph.D; Department of Radiopharmacy, Faculty of Pharmacy, Tehran University of Medical Sciences, Tehran, Iran.

Email: shafieeardestani@gmail.com

Tel/Fax: (+98) 2166959098 in many cases, adjuvants are required to induce more powerful immune responses.

Nanoparticles are recently assessed for their capacity to increase the immune responses as adjuvants [24]. However, more investigations on humans are required to establish their potential as vaccines against hepatitis B infection $[25,26]$. Dendrimers, a family of nanoscale three-dimensional polymers are defined as compact globular structures which have advantageous properties for application in drug delivery systems, compared to other polymers. Due to their limited polydispersity and nanometric scale, they can easily pass easily through biological barriers. In addition, during the process of dendrimer making, their size and molecular weight can be controlled precisely. The unique features of dendrimers such as their controllable size, monodispersity and variable surfaces make them desirable for biomedical applications. Furthermore, the end groups of dendrimers can be functionalized for therapeutic and imaging purposes as well as targeted drug delivery [27]. In this paper for the first time, a new biocompatible and biodegradable structure composed of a protein moiety (HBsAg) and a chemical segment (dendrimers) was generated in order to investigate the adjuvanticity effect of this nanocomplex. 


\section{MATERIALS and METHODS}

\section{Materials}

Polyethylene glycol 600 (PEG-600), citric acid, dicyclohexylcarbodiimide (DCC), dimethyl sulfoxide (DMSO), methanol, chloroform, iodine, toluene, calcium chloride anhydrous, acetone, curcumin and TLC Silica gel 60 were purchased from Merck (USA). Dialysis membranes (100$500 \mathrm{Da}$ and 500-1000 Da cutoffs) and HBsAg were obtained from Spectrum Co. (USA) and Production and Research Complex of Pasteur Institute of Iran, respectively.

\section{Dendrimer synthesis and antigen conjugation}

For dendrimer synthesis, $3.72 \mathrm{mmol}$ DCC was dissolved in 10 $\mathrm{ml}$ dry DMSO and added to a balloon containing $2 \mathrm{ml}$ PEG$600(3.7 \mathrm{mmol})$. The mixture was then stirred for about 15 minutes. Subsequently, $3.72 \mathrm{mmol}$ citricacid was added and stirred for $1 \mathrm{~h}$. Reaction was stopped by adding $10 \mathrm{ml}$ deionized distilled water $(\mathrm{ddH} 2 \mathrm{O})$ and filtered by a filter paper. The clear filtrate was collected and subjected into dialysis bag (cut off $100-500 \mathrm{Da}$ ). The bag was transferred into a flask containing $700 \mathrm{ml} \mathrm{ddH} 2 \mathrm{O}$ at room temperature under stirring condition. The ddH2O was continuously refreshed with $1 \mathrm{~h}$ intervals for $16 \mathrm{~h}$. The product was removed from the dialysis bag and dried using freeze-drying. Dendrimers ( $1 \mathrm{mmole})$ were conjugated to $\mathrm{HBsAg}(5 \mathrm{mg} / \mathrm{ml})$ in an EDC mediated reaction for $24 \mathrm{~h}$ at $4^{\circ} \mathrm{C}$. The conjugated $\mathrm{HBsAg}$ was purified by dialysis (Cutoff $10 \mathrm{kDa}$ ) as previously described and freezedried for further analysis.

\section{Characterization of physico-chemical properties of conjugated HBsAg}

Zeta potential and particle size were measured to determine the charge and size distribution of the conjugated HBsAg (Malvern Nano-ZS, UK). Water was used as a dispersant and the zeta potential values of the samples were measured at $24^{\circ} \mathrm{C}$. FT-IR spectra was also measured on a Bruker Model Tensor-27 spectrometer (Kyoto, Japan).

\section{Immunization Protocols}

For immunization, pathogen-free, female BALB/c mice $(20 \mathrm{~g}$ average weight) were used and handled according to the international animal care ethics. Groups of six mice were immunized at weeks 0,3 and 6 either subcutaneously (s.c.) in the tail base with $5 \mu \mathrm{g}$ of $\mathrm{HBsAg}$ or the nano-sized $\mathrm{Ag}$ resuspended in $100 \mu \mathrm{l}$ of PBS. After 2-weeks post- immunizations, mouse blood samples were collected by retroorbital bleeding and the sera were stored at $-70^{\circ} \mathrm{C}$ before testing.

\section{Immunoassays by ELISA}

Humoral response of the immunized mice was analyzed by ELISA method. Briefly, purified recombinant HBsAg $(1 \mu \mathrm{g} / \mathrm{ml}$, Pasteur Institute of Iran) was used as capture molecules to coat ELISA plates (96-well polyvinyl chloride plate-Nunc, Denmark) overnight at $4^{\circ} \mathrm{C}$. This dilution had been optimized to give the highest readings with positive control samples and the lowest background readings with naive serum samples. After washing and blocking steps, the wells were probed with serial dilutions of serum of each mouse $(1 / 100-1 / 3200)$, incubated for $1 \mathrm{~h}$, washed and further incubated with HRPlabeled goat anti-mouse IgG- $\gamma$ chain (Sigma, Aldrich) as secondary antibody. Finally, by addition of TMB (tetramethylbenzidine; Sigma, Aldrich) and color development, the absorbance was measured at $450 \mathrm{~nm}$. [20].

\section{RESULTS}

\section{Zeta potential and size distribution analysis}

The zeta potential and size distribution analyses of HBsAg and conjugated HBsAg were confirmed the conjugation reaction. Size distributions were 91.37 and $145.3 \mathrm{~nm}$ for $\mathrm{HBsAg}$ and conjugated HBsAg, respectively (Fig. 1).

Mean zeta potentials were obtained as -23.1 and $-33.7 \mathrm{mV}$ for HBsAg and conjugated HBsAg, respectively (Fig. 2).

\section{FT-IR spectrometry analysis}

FT-IR spectra demonstrated peaks regarding dendrimer were suppressed by HBsAg peaks. Peaks of 1639 and 2900-3000 $\mathrm{cm}-1$ were the significant signs of conjugation (Fig. 3).

Evaluation of HBs-specific total IgG

As shown in Fig. 4, both groups vaccinated with either the purified antigen or the conjugated antigen induced HBsspecific total $\mathrm{IgG}$, albeit in different intensities. Accordingly, conjugated HBsAg was capable of inducing higher levels of total IgG. These data showed the efficiency of nano-conjugated form of the antigen regimen in comparison with the antigen alone vaccination. These results showed that the conjugated form of the antigen was more immunogenic than the nonconjugated form.

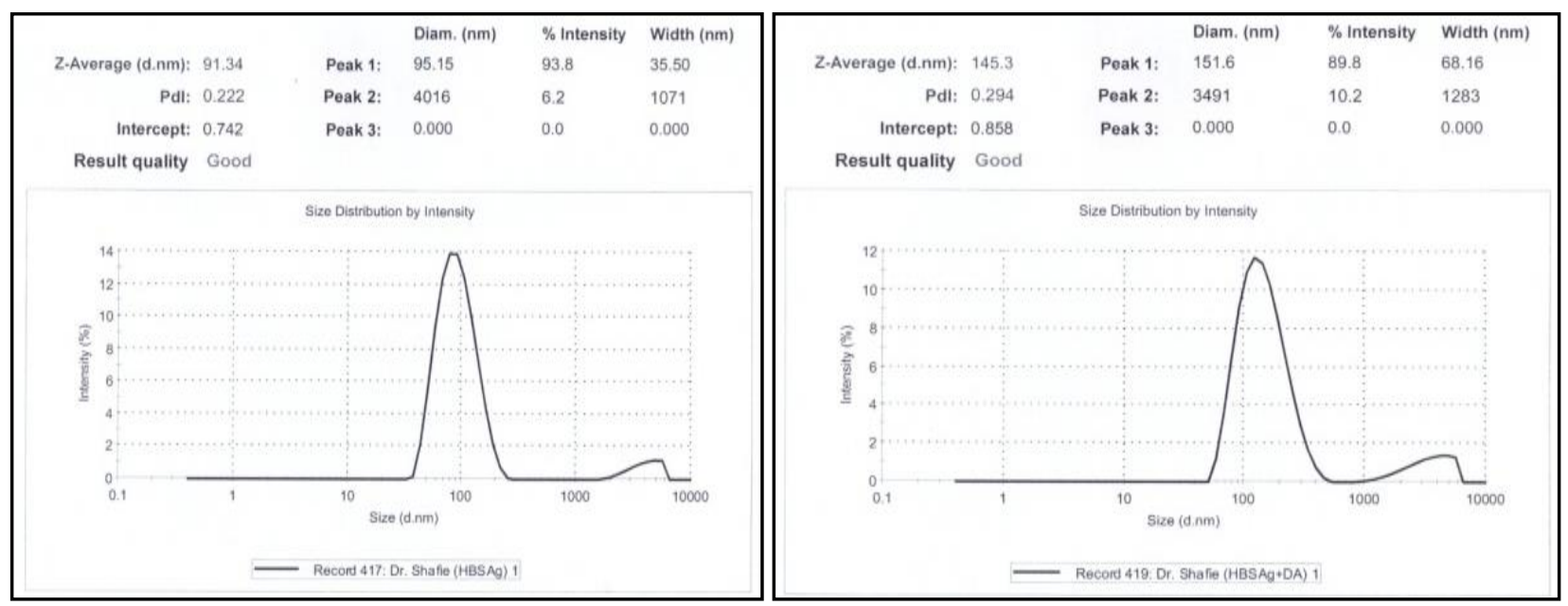

Fig. 1. Size distribution of HBsAg (Left) and conjugated HBsAg (Right). 

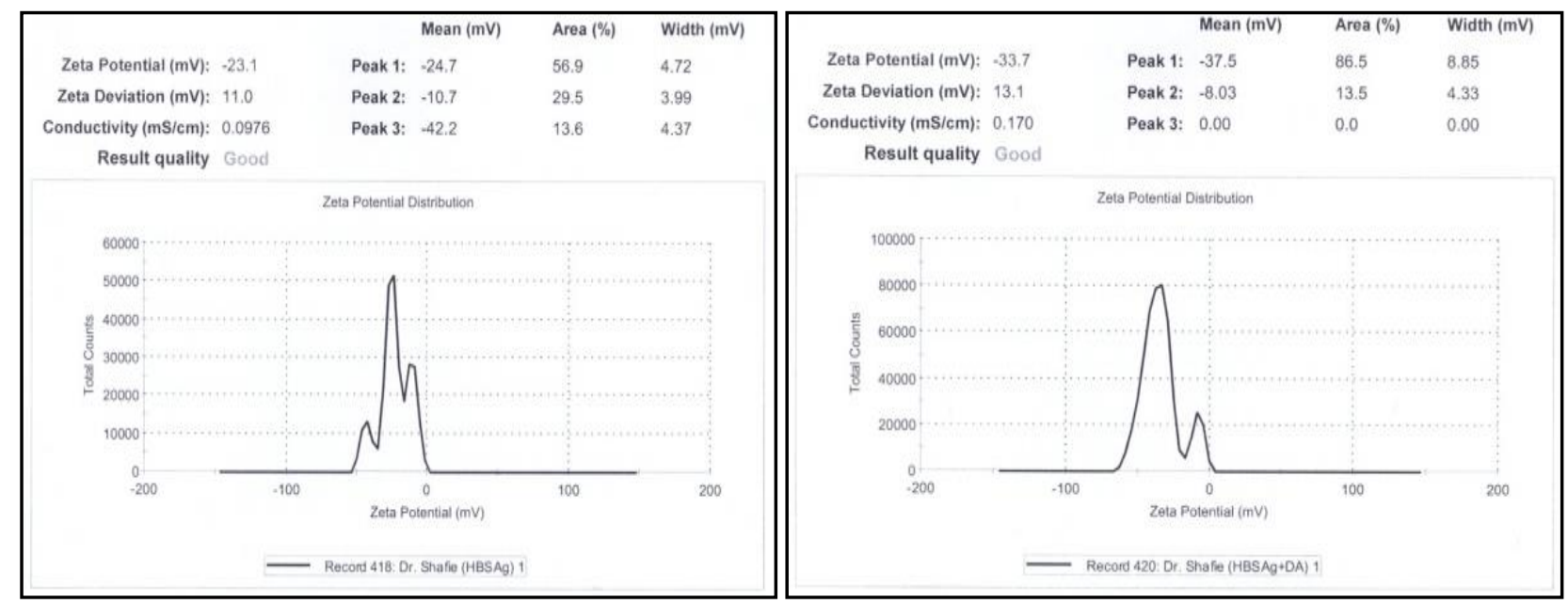

Fig. 2. Zeta potential of HBsAg (Left) and conjugated HBsAg (Right).

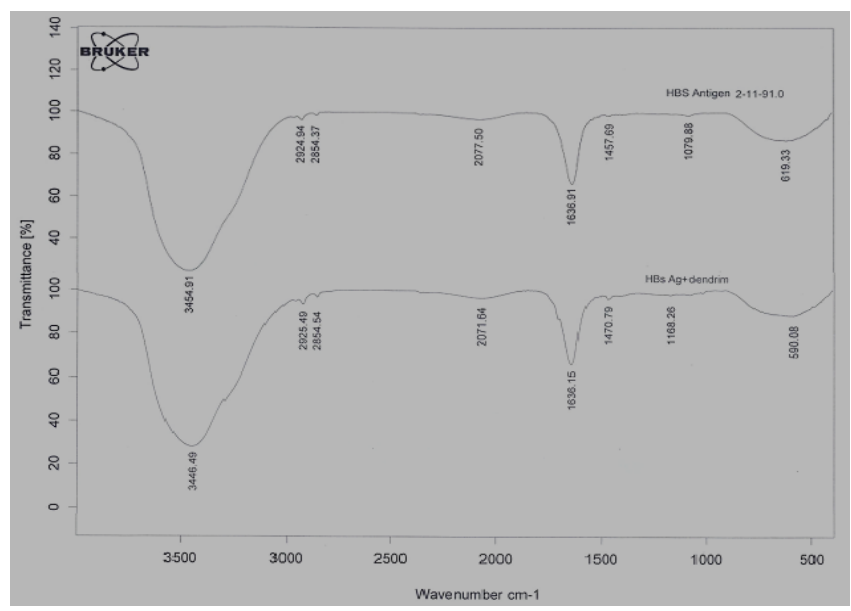

Fig. 3. FT-IR spectra analysis of HBsAg before and after conjugation with dendrime

\section{DISCUSSION}

Many studies have pursued suitable potential adjuvants to be used in commercial HBV surface antigen vaccine formulations [28-32]. Hepatitis B vaccine, when managed in conjunction with alum adjuvants, induces Th2 immunity that confers protection against HBV [32]. Mishra et al. have shown that Mannosylated solid lipid nanoparticles appear to be capable of functioning as carriers for vaccine delivery against hepatitis B as demonstrated by in vitro and in vivo experiments [27]. In 2013, the new nano-complex, Hep-c, was shown to improve the immunogenicity of the hepatitis B vaccine [33]. Lugade and colleagues have suggested that chitosan nanoparticle vaccines represent a promising un-adjuvanted platform to generate robust and durable immunity to $\mathrm{HBsAg}$ and other subunit antigens following a single low-dose administration [34]. However, based on the results of these studies, the currently available vaccine formulations and adjuvants do not provoke suitable Th1 and CTL responses that are important for inhibition of maternal transmission of the virus.

Many studies have been investigated the application of nanoparticles in vaccine development area [24, 34-37]. In the current study for the first time, a cost-effective, biodegradable and biocompatible polymer was used to enhance the immunogenicity of HBsAg. In contrast to linear polymers,

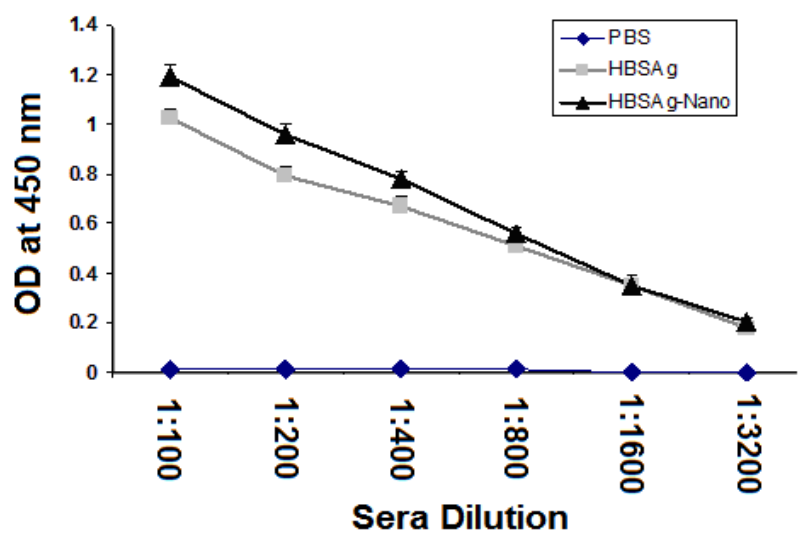

Fig. 4. Analysis of total IgG induced by different forms of the antigen. Each formulation is abbreviated on the diagrams (see the text for detailed materials and methods). Total IgG were determined at serial dilution of mice sera. Bars indicate Standard Deviation.

anionic globular dendrimers are composed of a polyethylene glycolic core and citric acid branches with a precisely controllable size and molecular weight. The presence of a large number of terminal citric acid ends increases the solubility and reactivity of the dendrimer. Water-soluble dendrimers, like anionic globular dendrimers, are able to connect to hydrophobic molecules with antifungal or antibacterial properties for medicinal goals [38]. In addition, they have potential properties like sustained or targeted delivery of compounds or proteins to living cells for tumortargeted drug and gene delivery systems [39]. The emergence of armed dendrimers with polyethylene glycolic core has led to generation of dendrimers with higher solubility in water and higher drug loading capacity as we used in this investigation [40].

In this study for the first time, a new biocompatible and biodegradable structure of $\mathrm{HBsAg}$ was generated by chemical conjugation between $\mathrm{HBsAg}$ and dendrimers and its immunogenicity was then characterized by immunoassays. Further biological assays are required for better characterization of such nano-sized version of HBsAg as a component of hepatitis B vaccine in future. 


\section{ACKNOWLEDGMENTS}

This research is partially supported by Pasteur Institute of Iran (IPI Grant\#527). The authors are declared their deep gratitude to all technicians who supported the project.

\section{CONFLICT of INTEREST}

The authors declare that they have no conflict of interest.

\section{REFERENCES}

1. Goldstein ST, Zhou F, Hadler SC, Bell BP, Mast EE, Margolis HS. A mathematical model to estimate global hepatitis B disease burden and vaccination impact. International journal of epidemiology. 2005;34(6):1329-39. doi:10.1093/ije/dyi206.

2. Ott JJ, Stevens GA, Groeger J, Wiersma ST. Global epidemiology of hepatitis B virus infection: new estimates of age-specific HBsAg seroprevalence and endemicity. Vaccine. 2012;30(12):2212-9. doi:10.1016/j.vaccine.2011.12.116.

3. Lavanchy D. Hepatitis B virus epidemiology, disease burden, treatment, and current and emerging prevention and control measures. Journal of vira hepatitis. 2004;11(2):97-107.

4. Garlich H, 2014.Prophylactic vaccination against hepatitis B: achievements, challenges and perspectives. Med Microbiol Immunol.

5. Couillin I, Pol S, Mancini M, Driss F, Brechot C, Tiollais P et al Specific vaccine therapy in chronic hepatitis $\mathrm{B}$ : induction of $\mathrm{T}$ cell proliferative responses specific for envelope antigens. The Journal of infectious diseases. 1999;180(1):15-26. doi:10.1086/314828.

6. Pol S, Driss F, Michel ML, Nalpas B, Berthelot P, Brechot C. Specific vaccine therapy in chronic hepatitis $B$ infection. Lancet. 1994;344(8918):342.

7. Pol S, Nalpas B, Driss F, Michel ML, Tiollais P, Denis J et al. Efficacy and limitations of a specific immunotherapy in chronic hepatitis B. Journal of hepatology. 2001;34(6):917-21.

8. Ren F, Hino K, Yamaguchi Y, Funatsuki K, Hayashi A, Ishiko $\mathrm{H}$ et al. Cytokine-dependent anti-viral role of CD4-positive T cells in therapeutic vaccination against chronic hepatitis B viral infection. Journal of medical virology. 2003;71(3):376-84. doi:10.1002/jmv.10509.

9. Safadi R, Israeli E, Papo O, Shibolet O, Melhem A, Bloch A et al. Treatment of chronic hepatitis $\mathrm{B}$ virus infection via oral immune regulation toward hepatitis $\mathrm{B}$ virus proteins. The American journal of gastroenterology. 2003;98(11):2505-15. doi:10.1111/j.15720241.2003.07700.x

10. Yalcin K, Acar M, Degertekin H. Specific hepatitis B vaccine therapy in inactive HBsAg carriers: a randomized controlled trial. Infection. 2003;31(4):221-5.

11. Wen YM, Wu XH, Hu DC, Zhang QP, Guo SQ. Hepatitis B vaccine and anti-HBs complex as approach for vaccine therapy. Lancet. 1995;345(8964):1575-6

12. Yao X, Zheng B, Zhou J, Xu DZ, Zhao K, Sun SH et al. Therapeutic effect of hepatitis B surface antigen-antibody complex is associated with cytolytic and non-cytolytic immune responses in hepatitis B patients. Vaccine. 2007;25(10):1771-9. doi:10.1016/j.vaccine.2006.11.019.

13. Wang XY, Zhang XX, Yao X, Jiang JH, Xie YH, Yuan ZH et al. Serum HBeAg sero-conversion correlated with decrease of HBsAg and HBV DNA in chronic hepatitis B patients treated with a therapeutic vaccine. Vaccine. 2010;28(51):8169-74 doi:10.1016/j.vaccine.2010.09.093.

14. Xu DZ, Zhao K, Guo LM, Li LJ, Xie Q, Ren H et al. A randomized controlled phase IIb trial of antigen-antibody immunogenic complex therapeutic vaccine in chronic hepatitis $\mathrm{B}$ patients. PloS one. 2008;3(7):e2565. doi:10.1371/journal.pone.0002565.

15. Xu DZ, Wang XY, Shen XL, Gong GZ, Ren H, Guo LM et al. Results of a phase III clinical trial with an HBsAg-HBIG immunogenic complex therapeutic vaccine for chronic hepatitis B patients: experiences and findings. Journal of hepatology. 2013;59(3):450-6. doi:10.1016/j.jhep.2013.05.003.

16. Mancini-Bourgine M, Fontaine $\mathrm{H}$, Brechot $\mathrm{C}$, Pol S, Michel ML. Immunogenicity of a hepatitis B DNA vaccine administered to chronic HBV carriers. Vaccine. 2006;24(21):4482-9. doi:10.1016/j.vaccine.2005.08.013.
17. Mancini-Bourgine M, Fontaine H, Scott-Algara D, Pol S, Brechot C, Michel ML. Induction or expansion of T-cell responses by a hepatitis B DNA vaccine administered to chronic HBV carriers. Hepatology. 2004;40(4):874-82. doi:10.1002/hep.20408.

18. Fontaine H, Kahi S, Chazallon C, Bourgine M, Varaut A, et al. AntiHBV DNA vaccination does not prevent relapse after discontinuation of analogues in the treatment of chronic hepatitis $\mathrm{B}$ : a randomised trialANRS HB02 VAC-ADN. Gut.doi:10.1136/gutjnl-2013-305707.

19. Godon O, Fontaine H, Kahi S, Meritet J, Scott-Algara D, Pol S et al Immunological and antiviral responses after therapeutic DNA immunization in chronic hepatitis B patients efficiently treated by analogues. Molecular therapy : the journal of the American Society of Gene Therapy. 2014;22(3):675-84. doi:10.1038/mt.2013.274.

20. Yoon SK, Seo YB, Im SJ, Bae SH, Song MJ, You CR et al. Safety and immunogenicity of therapeutic DNA vaccine with antiviral drug in chronic HBV patients and its immunogenicity in mice. Liver international : official journal of the International Association for the Study of the Liver. 2015;35(3):805-15. doi:10.1111/liv.12530.

21. Dahmen A, Herzog-Hauff S, Bocher WO, Galle PR, Lohr HF. Clinical and immunological efficacy of intradermal vaccine plus lamivudine with or without interleukin-2 in patients with chronic hepatitis B. Journal of medical virology. 2002;66(4):452-60.

22. Horiike N, Fazle Akbar SM, Michitaka K, Joukou K, Yamamoto K, Kojima $\mathrm{N}$ et al. In vivo immunization by vaccine therapy following virus suppression by lamivudine: a novel approach for treating patients with chronic hepatitis B. Journal of clinical virology : the official publication of the Pan American Society for Clinical Virology. 2005;32(2):156-61. doi:10.1016/j.jcv.2004.07.004.

23. Kosinska AD, Liu J, Lu M, Roggendorf M. Therapeutic vaccination and immunomodulation in the treatment of chronic hepatitis $\mathrm{B}$ : preclinical studies in the woodchuck. Medical microbiology and immunology. 2015;204(1):103-14. doi:10.1007/s00430-014-0379-5.

24. Asgary V, Kord Mafi O , Khosravy MS, Janani A, Namvar Asl N , Bashar R, et al. Evaluation of the Effect of Silver Nanoparticles on Induction of Neutralizing Antibodies against Inactivated Rabies

Virus.VacRes. 2014; 1:33-34.

25. Gordon D, Kelley P, Heinzel S, Cooper P, Petrovsky N Immunogenicity and safety of Advax, a novel polysaccharide adjuvant based on delta inulin, when formulated with hepatitis B surface antigen: a randomized controlled Phase 1 study. Vaccine. 2014;32(48):6469-77. doi:10.1016/j.vaccine.2014.09.034.

26. Li P, Tan H, Xu D, Yin F, Cheng Y, Zhang X et al. Effect and mechanisms of curdlan sulfate on inhibiting HBV infection and acting as an HB vaccine adjuvant. Carbohydrate polymers. 2014;110:446-55. doi:10.1016/j.carbpol.2014.04.025.

27. Kesharwani P, Iyer AK. Recent advances in dendrimer-based nanovectors for tumor-targeted drug and gene delivery. Drug discovery today. 2015;20(5):536-47. doi:10.1016/j.drudis.2014.12.012.

28. Jain AK, Goyal AK, Gupta PN, Khatri K, Mishra N, Mehta A et al. Synthesis, characterization and evaluation of novel triblock copolymer based nanoparticles for vaccine delivery against hepatitis B. Journal of controlled release : official journal of the Controlled Release Society. 2009;136(2):161-9. doi:10.1016/j.jconrel.2009.02.010.

29. Borges O, Silva M, de Sousa A, Borchard G, Junginger HE, Cordeiroda-Silva A. Alginate coated chitosan nanoparticles are an effective subcutaneous adjuvant for hepatitis B surface antigen. International immunopharmacology.

doi:10.1016/j.intimp.2008.08.013

30. Dutta T, Garg M, Jain NK. Poly(propyleneimine) dendrimer and dendrosome mediated genetic immunization against hepatitis B. Vaccine. 2008;26(27-28):3389-94. doi:10.1016/j.vaccine.2008.04.058.

31. Mishra H, Mishra D, Mishra PK, Nahar M, Dubey V, Jain NK. Evaluation of solid lipid nanoparticles as carriers for delivery of hepatitis B surface antigen for vaccination using subcutaneous route. Journal of pharmacy \& pharmaceutical sciences : a publication of the Canadian Society for Pharmaceutical Sciences, Societe canadienne des sciences pharmaceutiques. 2010;13(4):495-509.

32. Mishra H, Mishra D, Mishra PK, Nahar M, Dubey V, Jain NK. Evaluation of solid lipid nanoparticles as carriers for delivery of hepatitis B surface antigen for vaccination using subcutaneous route. Journal of pharmacy \& pharmaceutical sciences : a publication of the Canadian Society for Pharmaceutical Sciences, Societe canadienne des sciences pharmaceutiques. 2010;13(4):495-509.

33. Fakharzadeh S, Kalanaky S, Hafizi M, Goya MM, Masoumi Z, Namaki $S$ et al. The new nano-complex, Hep-c, improves the 
immunogenicity of the hepatitis B vaccine. Vaccine. 2013;31(22):2591-7. doi:10.1016/j.vaccine.2013.03.030.

34. Lugade AA, Bharali DJ, Pradhan V, Elkin G, Mousa SA, Thanavala Y. Single low-dose un-adjuvanted HBsAg nanoparticle vaccine elicits robust, durable immunity. Nanomedicine : nanotechnology, biology, and medicine. 2013;9(7):923-34. doi:10.1016/j.nano.2013.03.008.

35. Xu Y, Tang H, Liu JH, Wang H, Liu Y. Evaluation of the adjuvant effect of silver nanoparticles both in vitro and in vivo. Toxicology letters. 2013;219(1):42-8. doi:10.1016/j.toxlet.2013.02.010.

36. Yen HJ, Hsu SH, Tsai CL. Cytotoxicity and immunological response of gold and silver nanoparticles of different sizes. Small. 2009;5(13):1553-61. doi:10.1002/smll.200900126.
37. Niikura K, Matsunaga T, Suzuki T, Kobayashi S, Yamaguchi H, Orba $\mathrm{Y}$ et al. Gold nanoparticles as a vaccine platform: influence of size and shape on immunological responses in vitro and in vivo. ACS nano. 2013;7(5):3926-38. doi:10.1021/nn3057005.

38. Klajnert B, Bryszewska M. Dendrimers: properties and applications. Acta biochimica Polonica. 2001;48(1):199-208.

39. Nanjwade BK, Bechra HM, Derkar GK, Manvi FV, Nanjwade VK. Dendrimers: emerging polymers for drug-delivery systems. European journal of pharmaceutical sciences : official journal of the European Federation for Pharmaceutical Sciences. 2009;38(3):185-96. doi:10.1016/j.ejps.2009.07.008.

40. Medina SH, El-Sayed ME. Dendrimers as carriers for delivery of chemotherapeutic agents. Chemical reviews. 2009;109(7):3141-57. doi:10.1021/cr900174j. 